Anuario da Facultade de Dereito da Universidade da Coruña

Vol. 20 (2016), pp. 497-505

ISSNe: 2530-6324 || ISSN: 1138-039X

DOI: https://doi.org/10.17979/afdudc.2016.20.0.1957

\title{
LENA KUNZ \\ Postmortale Privatautonomie und Willensvollstreckung (Von der kanonischen voluntas pia zur Gestaltunsgmacht des Erblassers im deutsch-spanischen Rechtsvergleich). (Studien zum Europäischen Privatrecht und zur Rechtsvergleichung. Band 6). JWV Jenaer Wissenschaftliche Verlagsgesellschaft mbH, Jena 2015, 540 págs.
}

\author{
RAMÓN P. RODRÍGUEZ MONTERO \\ Prof. Titular de Derecho Romano \\ Universidade da Coruña
}

El interesante y muy completo trabajo de la Dra. Lena Kunz se concreta fundamentalmente, según manifiesta en la Introducción a su obra, en el intento de dar respuesta a la cuestión relativa a la que califica como "posible justificación del amplio poder de disposición del individuo" que se manifiesta en la producción de efectos con posterioridad a su muerte a partir de las decisiones tomadas en vida por éste sobre su patrimonio en previsión de su fallecimiento, organizando de forma eficaz lo que suceda cuando deje de existir y prorrogando, en definitiva, su autonomía privada más allá de su propia vida biológica. Todo ello mediante el recurso a la figura de la denominada "ejecución testamentaria", que es precisamente en la que la autora centra su atención.

Con la finalidad de dar respuesta a la cuestión planteada, la autora estructura su estudio en seis partes. Las dos primeras se encuentran dedicadas, respectivamente, a la metodología y objeto del trabajo: I: "Planteamiento del problema y método" (pp. 3762); II: "La ejecución testamentaria como objeto de análisis" (pp. 62-82). La tercera al análisis comparativo sobre los poderes dispositivos post mortem reconocidos al testador por el Derecho alemán y el español: III: "Los fundamentos jurídicos de la ejecución testamentaria en el Derecho español y alemán" (pp. 83-226). La cuarta, tras realizar una breve descripción de una serie de fuentes seleccionadas, al estudio del pensamiento jurisprudencial sobre la ejecución testamentaria: IV: "Los fundamentos jurídicos 
tradicionales de la ejecución testamentaria" (pp. 227-396). La quinta al análisis de los distintos modelos que pretenden explicar el actual reconocimiento y justificación al testador de poderes de disposición post mortem: V: "La autonomía privada del testador después de la muerte. Una hipótesis sobre la ejecución testamentaria" (pp. 397-438). Y, por último, la sexta, en la que se contiene un resumen y las conclusiones del trabajo: VI: "Resumen y conclusiones del estudio" (pp. 439-450). Completan a su vez el libro que nos ocupa otras tres secciones más, relativas respectivamente a cuatro Anexos (pp. 451480), Bibliografía (pp. 481-534), e Índice alfabético (535-540).

Entre los datos relevantes a tomar en consideración en materia de ejecución testamentaria, Lena Kunz destaca en su estudio que, respecto a dicha figura, en el Reglamento Europeo sobre Sucesiones (Reglamento (UE) n ${ }^{\circ}$ 650/2012 del Parlamento Europeo y del Consejo, de 4 de julio de 2012, relativo a la competencia, la ley aplicable, el reconocimiento y la ejecución de las resoluciones, a la aceptación y la ejecución de documentos públicos en materia de sucesiones mortis causa y a la creación de un certificado sucesorio europeo), el legislador europeo no ha optado por una solución de reconocimiento, sino por el establecimiento de una norma de conflicto, además de adoptar en su art. 29 una serie de normas especiales para ciertos Estados miembros de la Unión. Asimismo se hace eco de la introducción en los arts. 62-73 del mencionado Reglamento del denominado "certificado sucesorio europeo", que califica como "importante instrumento" que permite la legitimación de los ejecutores testamentarios en el tráfico jurídico europeo al poder probar sus facultades según la ley nacional aplicable en cada caso, surtiendo efectos directos en todos los Estados miembros sin tener por ello que ser sometido a ningún procedimiento especial previo de reconocimiento por los correspondientes tribunales o autoridades nacionales de los mismos.

Dicha circunstancia conduce a la Dra. Kunz a preguntarse en su trabajo por las posibles ventajas y desventajas que dicho reconocimiento trae consigo.

Para contestar a esta cuestión, tomando como referencia en la materia los ordenamientos jurídicos alemán y español, procede a realizar -desde la que califica como una "visión horizontal"- un análisis jurídico-comparativo de la ejecución testamentaria en dichos ordenamientos desde el punto de vista de sus funciones y facultades, orientada, según dice, a establecer las similitudes y diferencias entre sus respectivas regulaciones.

Con carácter previo al mencionado análisis también lleva a cabo en su trabajo un estudio histórico-jurídico de los fundamentos tradicionales que, en su opinión, muestran que la ejecución testamentaria no constituye de ninguna forma una constante atemporal, dado que la misma se encuentra firmemente consagrada en la vida jurídica europea desde al menos el siglo XIII de nuestra era en el ámbito del Derecho canónico clásico de la Iglesia romano-católica, al que la autora otorga un importante papel en el desarrollo de la citada ejecución testamentaria, dada la identidad de objetivos existentes entre el executor ad pias causas del citado Derecho canónico clásico y el actual ejecutor testamentario, que, en su opinión, aun a pesar de la existencia entre los mismos de importantes diferencias funcionales, se concretan en la común realización de la voluntad del testador.

Ciertamente, como indica Lena Kunz, el análisis histórico-jurídico y jurídicocomparativo de la ejecución testamentaria, permiten describir la actual figura jurídica de 
la misma de una forma muy completa, al hacerlo tanto desde una visión vertical, en su dimensión histórica de las ideas, como horizontal, en las distintas formas en que aparece regulada actualmente.

Por lo que se refiere al análisis de la ejecución testamentaria desde el punto de vista de las ideas, la autora destaca la circunstancia de que en el Derecho canónico clásico, al igual que ocurre en la actual ejecución testamentaria, el ejecutor testamentario también actuaba fundamentalmente según la última voluntad del testador, pero, en este caso, identificada con la voluntas pia. Así, en Derecho canónico clásico, la realización de esa voluntas pia manifestada por el testador se situaba en el centro de la executio.

En su opinión, antiguamente y al menos desde el siglo XIII, la voluntas pia era lo que justificaba que un testador pudiese influir sobre la posteridad más allá de su muerte, proyectando su voluntad hacia el otro mundo. Según la autora, la ejecución testamentaria cumplía en el Derecho canónico, principalmente, una finalidad de interés o utilidad pública, contribuyendo a la mejora espiritual religiosa y, por tanto, "al común de todos" al buscar el bienestar de la comunidad entendida ésta en términos abstractos, asegurando al testador la salvación del alma, sin que en la misma cupiese diferenciar la preocupación por el bienestar de los demás con el personal propio. Ello se debe a su entender a la circunstancia de que en el Derecho canónico de la Iglesia romano-católica no se establecía de forma clara una distinción funcional e institucional entre el/los heredero/herederos y el ejecutor testamentario, lo que, por el contrario, si ocurre en la actualidad.

Precisamente es en el centro de la ejecución testamentaria actual donde a su entender se sitúa la voluntad individual y los deseos personales del testador, cumpliendo sólo un interés particular o utilidad privada, sin servir, como por el contrario ocurría en la Edad Media, al común de todos. Y todo ello salvando la circunstancia de que el testador, también en la actualidad, al hacer uso de su capacidad de disposición post mortem pueda dejarse llevar por ideas no ya estrictamente particulares, sino por intereses asistenciales o altruistas, pero, en estos casos, con la importante diferencia respecto al antiguo Derecho canónico-clásico de que, frente a la ejecución testamentaria medieval, la actual preocupación por los demás no busca ya el bienestar de la comunidad entendida en términos abstractos como ocurría antiguamente, sino que, a lo sumo, se proyecta sobre un grupo pequeño y específico de beneficiarios.

En la actualidad, según Lena Kunz, lo que se ejecuta es, por tanto, una voluntad subjetiva, permitiendo al testador a través de la ejecución testamentaria alargar su voluntad más allá de su muerte, pero no proyectándola hacia el otro mundo, hacia el más allá, sino asegurándola en el nuestro, en el presente.

La ejecución testamentaria actual es para la autora una institución jurídica de interés privado y secularizada. La misma, al atribuir al testador una esfera de derecho patrimonial post mortem en este mundo, lo que resulta posible a través de la toma en consideración de la libertad de testar, entendida en un sentido subjetivo-individual y una vinculación de fidelidad entre el ejecutor testamentario y el testador-que se presenta, en opinión de Lena Kunz como la común matriz que aumenta el potencial de un recíproco reconocimiento de las facultades atribuidas al ejecutor testamentario por el Derecho español y al Testamentsvollstrecker del Derecho alemán- relativiza la diferenciación 
negativa entre estar vivo y estar muerto, inherente al B.G.B., y que, en todo caso, recoge el C.C. español.

La autora también alude en su monografía a la circunstancia de que esa proyección de la actual ejecución testamentaria al mundo presente, y no al otro mundo, se manifiesta especialmente en la estrecha vinculación existente entre la libertad de testar y la propiedad, entre el Derecho hereditario y los derechos reales, destacando en este punto concreto la diferencia apreciable entre los Derechos continentales y el Derecho inglés vigente, en el que, en su opinión, la ejecución testamentaria constituye plenamente un procedimiento jurídico-real y no de "Derecho hereditario", al establecerse el "personal representative" anglosajón, por exclusión de los beneficiarios, como un "legal owner" de los bienes hereditarios. Ello plantea problemas en relación a las normas de conflicto en cuanto a la posible calificación de dicha ejecución testamentaria como procedimiento jurídico-real o de Derecho hereditario. La solución a estos problemas cabría encontrarla en la consideración funcional -con exclusión de los herederos- de la figura regulada en los Derechos español y alemán como una autorización o legitimación fideicomisaria, puesto que, utilizando un concepto amplio del significado de fideicomiso - como acuerdo de fidelidad que va más allá de la muerte y que vincula al ejecutor testamentario y al testador-, podría lograrse la convergencia en la materia entre los diversos ordenamientos jurídicos implicados, es decir, el alemán, el español y el inglés.

Tras realizar el indicado estudio histórico-jurídico de los fundamentos tradicionales de la ejecución testamentaria desde el punto de vista de las ideas, partiendo de la que considera como "común matriz" de la ya señalada consideración de la libertad de testar -entendida en la actualidad en un sentido subjetivo-individual- y de la vinculación de fidelidad establecida entre el ejecutor testamentario y el testador -que considera como un elemento que aumenta el potencial de un recíproco reconocimiento de las facultades atribuidas al ejecutor testamentario español y al Testamentsvollstrecker alemán-, la autora procede seguidamente a analizar en su trabajo la ejecución testamentaria desde el punto de vista del derecho positivo, con la finalidad de intentar determinar, según explica, cuáles son los inconvenientes existentes en el ordenamiento jurídico español y alemán que dificultan dicho recíproco reconocimiento mutuo.

En virtud del indicado análisis jurídico-comparativo, señala cuatro importantes diferencias o "colisiones" apreciables en cada ordenamiento que plantean problemas de reconocimiento de la figura propia del país analizado en el otro.

En primer lugar, destaca que el ejecutor testamentario español -el denominado contador-partidor del art. 1057.1 del C. civil-, a diferencia del Testamentsvollstrocker alemán, puede llevar a cabo de forma efectiva una división material de la herencia, adjudicando a los herederos la propiedad de los bienes que la integran. No obstante, la autora recuerda que, aun cuando el principio de la adjudicación material no aparezca recogido expresamente en el B.G.B., el mismo no resulta extraño a la experiencia jurídica alemana.

En segundo lugar señala que en el Derecho hereditario alemán existe un numerus clausus de ejecutor testamentario y, por consiguiente, una delimitación jurídica del tipo. Las facultades jurídicas -entre las que no se encuentra contemplada ninguna relativa a la división de los bienes hereditarios, motivo por el cual el testador no puede otorgar al ejecutor testamentario ningún poder de división material de los bienes de la 
herencia- y limitaciones del ejecutor testamentario se encuentran recogidas en los arts. 2197 y ss. del B.G.B. Sin embargo, en el Derecho hereditario español no existe un numerus clausus, ni tampoco una delimitación o restricción legal de los diversos tipos. $\mathrm{Y}$ esto es algo que, frente a lo que ocurre en el ordenamiento jurídico alemán, da lugar a que en el ordenamiento jurídico español las facultades jurídicas del ejecutor testamentario no se encuentren legalmente delimitadas, derivando en este caso las mismas de las disposiciones testamentarias establecidas por la voluntad del testador, todo lo cual, como pone de manifiesto la autora en su estudio, provoca, según se ha indicado, importantes colisiones interpretativas de la figura propia del país de que se trate cuando las disposiciones testamentarias se analicen con los parámetros del ordenamiento jurídico contrario.

En tercer lugar, resalta otra diferencia significativa en materia de ejecución testamentaria entre el Derecho español y alemán, que concreta en la circunstancia de que, mientras que en el ordenamiento jurídico español se atribuye un peso importante a las legítimas y se enfatiza la relación familiar como un valor jurídico-hereditario decisivo, limitándose la libertad de testar y reduciéndose la presencia post mortem del testador en beneficio de sus miembros familiares directos, impidiéndose legalmente que un tercio de la herencia pueda ser objeto de disposición por parte del ejecutor testamentario, en el ordenamiento jurídico alemán, por el contrario, resulta posible apreciar -aun a pesar de protegerse también los derechos de los legitimarios- una mayor libertad testamentaria del testador, permitiéndosele según lo dispuesto en el art. 2306 del B.G.B. tener influencia post mortem sobre sus herederos con derecho a una cuota legítima, al reconocer únicamente a los mismos un derecho de elección, pero no una parte de la herencia -como ocurre en el ordenamiento español-, ofreciéndoseles la posibilidad de rechazar su cuota hereditaria si el testador hubiese ordenado realizar una ejecución testamentaria, en cuyo caso se establece que, al heredero que hiciese uso de este derecho, sólo le quedaría su derecho jurídico obligacional a la cuota legítima que le correspondiese, y, además, perdería su condición de heredero testamentario.

Finalmente, la cuarta diferencia apreciable entre el ordenamiento jurídico español y el alemán en materia de ejecución testamentaria la encuentra en el hecho de que, mientras que en el Derecho español la ejecución testamentaria se divide conceptualmente en tres partes o áreas de actividad, asignando a cada una de ellas una figura distinta -administración de la herencia; liquidación de la herencia; y división de la herencia-, en el Derecho alemán, en cambio, esas tres áreas o actividades se concentran en la única figura del ejecutor testamentario (arts. 2197 ss. B.G.B.).

No obstante lo indicado, la autora también matiza al respecto que, aun a pesar de la existencia de la discrepancia indicada, la misma, en esencia, es relativa, puesto que, al igual que en el Derecho alemán, en el español se parte dogmáticamente de una concepción unitaria de la ejecución testamentaria, y en éste, en base a la denominada "tesis de la absorción, cualquiera de las figuras que se ocupan en principio de forma específica e individualizada de cada una de las tres áreas o partes indicadas administración, liquidación y división de la herencia, respectivamente- puede asumir las tareas o facultades específicamente encomendadas a las otras.

Tras haber analizado los posibles puntos de intersección entre el Derecho español y alemán, considerando que la ejecución testamentaria supone la administración, liquidación y división de la herencia, Lena Kunz concluye que existen 
unos límites al recíproco reconocimiento de la figura del ejecutor testamentario con las características que aparece regulado en cada uno de esos dos ordenamientos jurídicos.

Desde la perspectiva del Derecho alemán, el límite se encuentra en el poder de adjudicación que tienen conferido los ejecutores testamentarios españoles, lo que, por el contrario, no ocurre en el ordenamiento jurídico alemán, en el que el ejecutor testamentario no es, en ningún caso, un adjudicador del resultado de la división de la herencia. Desde la perspectiva del Derecho español el límite se concreta en la capacidad de disposición que el ejecutor testamentario alemán tiene sobre lo que en el ordenamiento jurídico español se conoce como la legítima, que en dicho ordenamiento jurídico, frente a lo que ocurre en el alemán, resulta indisponible por el ejecutor testamentario español.

Llegada a este punto, la autora se pregunta si, a partir de lo establecido en los dos ordenamientos jurídicos analizados -alemán y español-, resulta posible desarrollar un régimen jurídico mejorado -textualmente habla de "mejor Derecho"- que fuese aplicable al que en terminología propia define como "ejecutor testamentario autónomoeuropeo".

Antes de contestar a la pregunta formulada, por lo que al concreto objeto de su trabajo se refiere, sugiere la necesidad de disponer en el ámbito del Derecho internacional privado sucesorio europeo de un único espacio jurídico-cultural lógicamente también hispano-alemán-, que, en su opinión y como se pone de manifiesto en el art. 81, apartado $2^{\circ}$ del Tratado de Funcionamiento de la UE., implica algo más que la referencia a un simple mercado interior. Ese espacio jurídico-cultural serviría a su entender como motivo para la armonización de las normas de conflicto o, en su caso, para la confección de nuevas normas de Derecho material sucesorio. Un Derecho sucesorio que, según Lena Kunz, de un tiempo a esta parte, ha perdido la importancia que anteriormente tenía, y que constituye no sólo una materia jurídica revestida de cuestiones patrimoniales y económicas, sino también de cuestiones muy personales desde su consideración como intersección entre la vida y la muerte.

En cuanto al régimen jurídico mejorado -"mejor Derecho" aplicable al "ejecutor testamentario autónomo europeo"- realiza diversas consideraciones y propuestas.

Entre las mismas, en primer lugar, sugiere la utilidad de establecer a nivel europeo un catálogo en el que, partiendo del sistema de numerus clausus alemán, se fijen con carácter taxativo las facultades jurídicas del ejecutor testamentario europeo. Ello, en su opinión, por una parte, proporcionaría seguridad jurídica, claridad y estabilidad al sistema; por otra, serviría como referente para indicar el camino a seguir con la finalidad de dar cabida en la figura a las distintas especificidades nacionales, además de actuar como hilo conductor en la ponderación entre los intereses del testador y de los herederos, y, en cualquier caso, aseguraría que la voluntad de aquél se cumpliese automáticamente, sin necesidad de tener que acudir con carácter previo para ello a juicio.

En segundo lugar, propone establecer un catálogo de facultades jurídicas sucesorias permanentes y de facultades jurídicas sucesorias variables como categorías aplicables al ejecutor testamentario a nivel europeo, tomando para ello en consideración la diferencia establecida en el régimen jurídico español entre "actos de administración" y "actos de disposición", que, a su juicio, presenta la ventaja de acompasarse mejor con 
las tareas del ejecutor testamentario que la división en "facultades de disposición" y "facultades de obligación" que adopta el sistema alemán (arts. 2205 y s. B.G.B.) en virtud del "principio de abstracción", que, al margen del ordenamiento jurídico alemán, resulta desconocido casi por completo en los demás ordenamientos. Según la autora, la aludida división en "actos de administración" y "actos de disposición" podría ayudar a mejorar la regulación a nivel europeo de la función del ejecutor testamentario.

En tercer lugar, se cuestiona en esta parte de su estudio la oportunidad o no de atribuir al ejecutor testamentario europeo la facultad jurídica de realizar la adjudicación material de los bienes hereditarios.

En su opinión, la atribución de la facultad jurídica de la adjudicación al ejecutor testamentario -que el Derecho español atribuye al "contador partidor", y cuyo reconocimiento rechaza, pero que no desconoce el Derecho alemán, desde una concepción autónoma como "Adjudikationbefugnis" en contraposición a la "Dispositionsbefugnis"- refuerza la libertad testamentaria del testador y, por consiguiente, su influencia post mortem en detrimento de sus herederos.

El alcance que quiera atribuirse a la autonomía privada post mortem del testador, del que también depende el reconocimiento a nivel europeo de la facultad jurídica de la adiudicatio, es una cuestión cuya valoración, según Lena Kunz, corresponde realizar al legislador.

Para la autora, la aludida atribución de la facultad jurídica de adjudicación de la herencia -que, en su opinión (ya fuese atribuida bien al juez, al propio testador, o, en su caso y por lo que aquí interesa, al propio ejecutor testamentario) ayudaría a mediar los conflictos que pudiesen plantearse entre los coherederos, "aliviando emocionalmente" a la comunidad hereditaria y evitando largas y caras disputas sucesorias entre los mismostiene que ser regulada con el debido cuidado, rigor y minuciosidad, pensando especialmente en el posible peligro que representa la circunstancia de que el contadorpartidor no cuente con la absoluta confianza de los herederos con la finalidad de llevar a cabo su cometido, corriendo en caso contrario el peligro de que aquél trate de comportarse como dueño de la herencia, acentuando de esta forma, y no remediando, posibles conflictos en el ámbito de la comunidad hereditaria.

Precisamente para poder llevar a cabo la aludida regulación con las necesarias garantías y elegir el procedimiento más adecuado en la práctica, sugiere tomar en consideración las distintas experiencias jurídico-prácticas de los respectivos Estados miembros de la Unión Europea.

Por último, la autora finaliza su trabajo preguntándose sobre la búsqueda de una posible causa communis para la ejecución testamentaria.

Tras constatar la existencia de múltiples aspectos problemáticos entre el Derecho alemán y español en el exhaustivo análisis jurídico comparativo realizado de la figura del ejecutor testamentario, precisa que la cuestión central se concreta en determinar si se debe limitar el poder jurídico de aquél, y, en caso afirmativo, en qué medida, considerando necesario para ello proceder a establecer las correspondientes limitaciones a la libertad de testar. 
La respuesta a esta pregunta considera que depende, fundamentalmente, del espacio post mortem que se atribuya al testador, es decir, del alcance que se otorgue a la autonomía privada post mortem del testador, que se presenta como obligado punto de referencia.

En su opinión, la determinación se ese alcance conecta, a su vez, con la cuestión relativa a cuáles son los intereses prioritarios que un ordenamiento jurídico europeo debería intentar proteger: ¿los de la herencia?; ¿los de los beneficiarios de la herencia?; ¿los del tráfico jurídico?; ¿o los del testador?. A su juicio, dichos intereses deben necesariamente ser ordenados.

Para Lena Kunz, la cuestión relativa al poder jurídico otorgable al ejecutor testamentario depende en gran medida de los motivos que justifiquen la propia existencia de tal institución. Del análisis histórico de las fuentes la autora alemana extrae la conclusión de que la figura, en los siglos XII y XIII, como ya se ha señalado, encontraba su legitimidad en la causa pia, colocando al ejecutor testamentario al servicio del cumplimiento de unos objetivos piadosos, encargándosele la transmisión de la voluntad de Dios. En la actualidad, sin embargo, la ejecución testamentaria encuentra su legitimidad en la voluntad subjetiva-individual, que, según la autora, ha pasado a ocupar el puesto de la causa pia, encargándose al ejecutor testamentario "transportar" como figura secularizada la transmisión de la voluntad del hombre.

El ejecutor testamentario cumple en cada momento histórico, por tanto, la función de ser el portador de un determinado propósito u objetivo. De esta forma, la reflexión histórica de la ejecución testamentaria nos muestra en opinión de la autora que la cuestión relativa a la determinación de las facultades jurídicas del ejecutor testamentario europeo depende, en esencia, de conseguir encontrar a nivel europeo una finalidad común para la indicada figura.

A nuestro juicio, la investigación realizada, tanto por su planteamiento y desarrollo metodológico, como por su amplio y detallado contenido merece una valoración muy positiva.

No solamente se analiza en el mismo de forma exhaustiva y rigurosa los fundamentos, facultades, funciones, finalidades y limitaciones jurídicas de la figura del ejecutor testamentario en relación con los poderes de disposición post mortem del testador, tanto desde una perspectiva histórico-jurídica -con especial atención al Derecho canónico clásico-, como desde una visón jurídico-comparativa -centrada en los ordenamientos alemán y español-, sino que, yendo mucho más allá, en atención a lo establecido respecto a la figura por el Reglamento europeo sobre sucesiones (Reglamento (UE) no 650/2012 del Parlamento Europeo y del Consejo, de 4 de junio de 2012), se cuestiona la posibilidad de desarrollar -atendiendo a la regulación efectuada por los ordenamientos jurídico alemán y español- un régimen jurídico mejorado, aplicable dentro de un único espacio jurídico-cultural europeo al que se denomina como "ejecutor testamentario autónomo-europeo", realizando al respecto para ello una serie de interesantes y sugerentes propuestas claramente razonadas.

Finalmente, consideramos que resulta obligado felicitar a la Dra. Lena Kunz por la capacidad intelectual y rigor científico cumplidamente demostrados en el interesante y sugerente libro del que ahora damos noticia, que, a nuestro juicio, reúne los siempre 
necesarios requisitos de calidad exigibles y que, en bastantes ocasiones, desgraciadamente, resultan preteridos. 